\title{
BMI open Outcomes of transplantation of livers from donation after circulatory death donors in the UK: a cohort study
}

Christopher J Callaghan, ${ }^{1}$ Susan C Charman, ${ }^{2,3}$ Paolo Muiesan, ${ }^{4}$ James J Powell, ${ }^{5}$ Alexander E Gimson, ${ }^{1}$ Jan H P van der Meulen, ${ }^{2,3}$ on behalf of the UK Liver Transplant Audit

To cite: Callaghan CJ, Charman SC, Muiesan P, et al. Outcomes of transplantation of livers from donation after circulatory death donors in the UK: a cohort study. BMJ Open 2013;3:e003287. doi:10.1136/bmjopen-2013003287

- Prepublication history for this paper is available online. To view these files please visit the journal online (http://dx.doi.org/10.1136/ bmjopen-2013-003287).

Received 22 May 2013 Revised 15 July 2013 Accepted 16 July 2013

${ }^{1}$ Cambridge Transplant Centre, Addenbrooke's Hospital, Cambridge, UK ${ }^{2}$ Clinical Effectiveness Unit, Royal College of Surgeons of England, London, UK ${ }^{3}$ Department of Health Services Research and Policy, London School of Hygiene and Tropical Medicine, London, UK

${ }^{4}$ Department of Liver Transplantation and Hepatopancreatobiliary Surgery, Queen Elizabeth Hospital, Birmingham, UK ${ }^{5}$ Scottish Liver Transplant Unit, Royal Infirmary of Edinburgh, Edinburgh, UK

\section{Correspondence to}

Dr Jan H P van der Meulen; jan.vandermeulen@|shtm.ac. uk

\section{ABSTRACT}

Objectives: Outcomes of liver transplantations from donation after circulatory death (DCD) donors may be inferior to those achieved with donation after brain death (DBD) donors. The impact of using DCD donors is likely to depend on specific national practices. We compared risk-adjusted graft loss and recipient mortality after transplantation of DCD and DBD livers in the UK.

Design: Prospective cohort study. Multivariable Cox regression and propensity score matching were used to estimate risk-adjusted HR.

Setting: 7 liver transplant centres in the National Health Service (NHS) hospitals in England and Scotland.

Participants: Adults who received a first elective liver transplant between January 2005 and December 2010 who were identified in the UK Liver Transplant Audit. Interventions: Transplantation of DCD and DBD livers. Outcomes: Graft loss and recipient mortality.

Results: In total, 2572 liver transplants were identified with $352(14 \%)$ from DCD donors. 3-year graft loss $(95 \% \mathrm{Cl})$ was higher with DCD livers $(27.3 \%, 21.8 \%$ to $33.9 \%$ ) than with DBD livers (18.2\%, $16.4 \%$ to $20.2 \%$ ). After adjustment with regression, HR for graft loss was 2.3 (1.7 to 3.0). Similarly, 3-year mortality was higher with DCD livers $(19.4 \%, 14.5 \%$ to $25.6 \%)$ than with DBD livers $(14.1 \%, 12.5 \%$ to $16.0 \%)$ with an adjusted $H R$ of 2.0 (1.4 to 2.8). Propensity score matching gave similar results. Centre-specific adjusted HRs for graft loss and recipient mortality seemed to differ among transplant centres, although statistical evidence is weak ( $p$ value for interaction 0.08 and 0.24 , respectively).

Conclusions: Graft loss and recipient mortality were about twice as high with DCD livers as with DBD livers in the UK. Outcomes after DCD liver transplantation may vary between centres. These results should inform policies for the use of DCD livers.

\section{INTRODUCTION}

The increasing disparity between the demand and supply of donor livers is a major challenge. The need to increase the donor pool, and improve organ utilisation, has led to the

\section{ARTICLE SUMMARY}

Article focus

- There is increasing disparity between demand and supply of donor livers for transplantation.

- The use of livers from donation after circulatory death (DCD) donors-in addition to those from donation after brain death (DBD)-increases the donor pool.

- We compared graft loss and recipient mortality after transplantation of DCD and DBD livers in the UK.

\section{Key messages}

- Recipients of DCD livers, after risk adjustment, have approximately twice the risk of graft loss and death within 3 years of transplantation than recipients of livers from DBD donors.

- The impact of using DCD livers on graft loss and recipient mortality seemed to differ among the seven UK transplant centres.

Strengths and limitations of this study

- A national database was used with near-complete inclusion of all liver transplantations in the UK with high data quality and follow-up, which eliminates the risk or selective reporting.

- Both multivariable regression analysis and propensity score matching were used to adjust for differences risk factors for graft loss and patient mortality between DBD and DCD donors and recipients.

- We were not able to assess the impact that time from withdrawal of life-sustaining treatment to cardiac arrest has on post-transplant outcomes of DCD livers.

reintroduction and rapid expansion of the use of livers from donation after circulatory death (DCD) donors. These donors have been classified as either uncontrolled, where cardiac arrest has occurred unexpectedly (Maastricht categories I and II), or controlled, where potential donors have life-sustaining treatment withdrawn after further interventions are deemed futile (Maastricht III), or circulatory 
death occurs in a donation after brain death (DBD) donor (Maastricht IV). ${ }^{1}$

Unlike DBD donors, livers from DCD donors undergo a variable period of warm ischaemia, during which time irreversible cellular damage may occur. Reliably measuring the warm ischaemic period is difficult outside of hospital, which means that the use of livers from uncontrolled DCD donors is limited. ${ }^{2}$ In contrast, planned withdrawal of lifesustaining treatment in Maastricht III donors enables close cardiorespiratory monitoring, provision of a prepared procurement team and minimisation of subsequent warm ischaemia. As such, the use of livers from controlled DCD donors has risen dramatically in the $\mathrm{USA}^{3}$ and Europe. ${ }^{4}$

US registry analyses have demonstrated that DCD liver transplantation has worse graft and patient survival than DBD liver transplantation. ${ }^{5-9}$ This is thought to be predominantly due to a higher rate of biliary complications in DCD livers than other causes of graft loss. ${ }^{10}$ Recognition of these issues has perhaps contributed to a recent drop in the number of DCD livers transplanted in the USA. ${ }^{311}$ However, as a result of encouraging early reports ${ }^{12}$ and decreasing DBD liver transplantation rates, the use of DCD livers in the UK is now more widespread than in the USA.

As there are differences between UK and US practice with respect to how DCD livers are being used, ${ }^{13}{ }^{14}$ we report in this article graft loss and recipient mortality after transplantation of DCD and DBD livers in the UK. Two risk-adjustment techniques were used to control for differences in donor and recipient risk factors.

\section{MATERIALS AND METHODS \\ Inclusion criteria}

Using data submitted to the UK Liver Transplant Audit, ${ }^{15}$ we identified all adult patients (aged $>16$ years) receiving a first liver transplant in the seven UK transplant centres between 1 January 2005 and 31 December 2010. Follow-up ceased on 31 March 2011. Regular checks indicate that data are consistently more than $93 \%$ complete and accurate. ${ }^{16-18}$ Patients receiving living or domino donors were excluded, as were those having an emergency ('super urgent $^{19}$ ) or multiorgan transplant. We are not aware of any uncontrolled DCD liver transplants having been performed in the UK during the study period.

\section{Donor and recipient selection and organ procurement}

Criteria for DCD donor selection and acceptable postwithdrawal haemodynamic parameters varied among the liver transplant centres, but were broadly based on the experience of Muiesan $e t a l,{ }^{12}$ and in line with US guidelines. ${ }^{19}$ Administration of heparin or vasodilators, or predissection of femoral vessels before death, is prohibited by law in the UK. Death was declared after cardiorespiratory arrest with a minimum interval of $5 \mathrm{~min}$. All UK liver procurement centres used a super-rapid recovery technique ${ }^{19}$ although preservation fluid type, bag pressure and the use of dual perfusion techniques varied.
Livers from DCD and DBD donors were allocated locally, and centres chose recipients according to local criteria. ${ }^{20}$ Optimal livers from DBD donors were offered to paediatric centres for splitting and implantation of the left lateral segment, with implantation of the extended right lobe into an adult recipient.

\section{Statistical analyses}

Pearson's $\chi^{2}$ test was used to identify differences of categorical variables and Student's t test or Mann-Whitney test for differences of continuous variables. Graft and recipient survival after transplantation were estimated using Kaplan-Meier methods. Graft loss was defined as retransplantation or death, regardless of perceived graft function at the time of death. Cold ischaemic time (CIT) was defined as the duration from the start of cold perfusion of the liver in the donor to organ removal from ice immediately prior to implantation.

A multivariable Cox regression model was used to adjust the comparisons of graft loss and recipient mortality between DCD and DBD livers for differences in risk factors at the time of transplantation. The donor, recipient and operative characteristics presented in tables 1 and 2 were included in the model. UK End-Stage Liver Disease (UKELD) and Model for End-Stage Liver Disease (MELD) scores were calculated for recipients, ${ }^{21}{ }^{22}$ but these scores were not incorporated in the multivariable model as the component variables of both were already included.

To test whether the impact of using DCD livers on graft loss and patient mortality varied among UK transplant centres, we included an interaction term of donor type and centre in the Cox model. The likelihood ratio test was used to test the statistical significance of the risk factors. The results of the survival analyses are presented as $\mathrm{HR}$ with $95 \% \mathrm{CI}$.

An analysis with propensity score matching was also conducted. The propensity score is the probability that a recipient would have received a liver from a DCD (as opposed to DBD) donor, based on observed donor and recipient characteristics. A logistic regression model was used to generate the propensity score. ${ }^{23}$ Donor type was regressed on main effects only and donor, recipient and operative characteristics were selected using a stepwise process with conservative removal $(p>0.20)$ and entry criteria $(p<0.10)$. We considered all two-way interactions of the main effects and explored non-linear relationships by including quadratic terms of continuous model factors. All interactions and quadratic terms with a $\mathrm{p}$ value $<0.05$ were selected. We estimated the propensity score based on the logistic regression model as the sum of the products of the model factors and their coefficients. Then, for each recipient in the DCD group we selected an individual from the DBD group by matching on the log of the estimated propensity score, using a nearest-neighbour matching algorithm with callipers (an interval) of maximum width of 0.2 SDs. We compared the 
Table 1 Donor characteristics by donor type

\begin{tabular}{|c|c|c|c|c|}
\hline $\begin{array}{l}\text { Liver donor type } \\
\text { Donor characteristics }\end{array}$ & $\operatorname{DCD}(n=352)$ & DBD $(n=2220)$ & p Value & Missing (n) \\
\hline Age, years & $42(16)$ & $46(15)$ & $<0.01$ & 0 \\
\hline Male sex & $206(59)$ & $1158(52)$ & 0.03 & 0 \\
\hline $\mathrm{BMI}, \mathrm{kg} / \mathrm{m}^{2}$ & $25(4)$ & $26(7)$ & $<0.01$ & 20 \\
\hline Serum sodium, $\mathrm{mmol} / \mathrm{L}$ & $144(140-150)$ & $147(142-154)$ & $<0.01$ & 4 \\
\hline Diabetes & $14(5)$ & $111(5)$ & 0.93 & 154 \\
\hline \multicolumn{5}{|l|}{ Organ appearance } \\
\hline Healthy & $176(70)$ & $1384(76)$ & 0.05 & 497 \\
\hline Suboptimal & $75(30)$ & $440(24)$ & & \\
\hline \multicolumn{5}{|l|}{ Cause of death } \\
\hline Trauma & $81(23)$ & $256(12)$ & $<0.01$ & 23 \\
\hline Stroke & $173(50)$ & $1546(70)$ & & \\
\hline Anoxia & $54(16)$ & $198(9)$ & & \\
\hline Other & $37(11)$ & $204(9)$ & & \\
\hline
\end{tabular}

distribution of all model factors in the DCD and DBD groups to assess the success of the propensity score model. The above processes were repeated for each of the 10 imputed data sets (see below for a description of methods to deal with missing data). The balance in the covariates across the treatment groups was considered to be achieved if the standardised differences were less than $10 \% .^{24}$ Cox regression was then performed on each of the 10 sets of matched pairs to estimate the effect of donor type on patient and graft survival. A robust $\mathrm{SE}$ was used to allow for the clustering on the pairs. The estimates were then combined using Rubin's rules to provide adjusted HRs and their $95 \%$ CI.

In addition to the donor, recipient and operative characteristics presented in tables 1 and 2, we also considered the following characteristics as candidates for inclusion in the propensity score model (all are yes/no unless otherwise stated): lifestyle activity score on fivepoint scale, liver failure grade (acute/not acute), encephalopathy grade on five-point scale, oesophageal varices, diuretic therapy, fever, sepsis, haemoglobin, white cell count, platelet count, serum urea, anticytomegalovirus status and antihepatitis $\mathrm{C}$ virus status. Types of biliary and hepatic arterial anastomoses were also considered as was the use of antifibrinolytic therapy.

\section{Missing values}

All model factors had missing values for less than $5 \%$ of patients with the exception of donor history of diabetes (7\%) and donor organ appearance (19\%). Multiple imputation using chained equations was used to fill in missing values. The imputation model included the model factors above, type of donor as well as terms representing the outcome (log of survival time and the censoring indicator).$^{25}$ We created 10 imputed data sets, and the model parameters based on these data sets were combined using Rubin's rules.

\section{RESULTS}

We identified 2572 first elective adult liver transplants. Of these, 352 (14\%) had a graft from a DCD donor. Use of livers from DCD donors progressively increased from $6.9 \%$ in 2005 to $26.3 \%$ in 2010 , an almost four-fold rise over that time period. Two centres used DCD donor livers in more than $30 \%$ of first elective adult liver transplants in 2010 .

\section{Donor, recipient and operative characteristics}

Compared to DBD liver donors, DCD donors were younger, had lower body mass indices, lower serum sodium concentrations and were more likely to be men (table 1). Although a similar proportion of organs appeared normal in the two groups, DCD donors had a higher proportion of missing values $(29 \%)$ than DBD donors $(18 \%)$. The cause of death for DBD donors was predominantly stroke $(70 \%)$, whereas the corresponding proportion in the DCD group was $49 \%$. Trauma was more common in DCD donors $(23 \%)$ than in DBD donors $(11 \%)$. In 352 DCD donors, the median (IQR) time from withdrawal of life support to cardiac arrest was 15 (11-20) min, whereas the median duration from cardiac arrest to cold perfusion was 12 (9-14) min.

Recipients of a DCD liver were more likely to be older, men, have lower serum bilirubin concentration and cancer as the primary liver disease (table 2). Both UKELD and MELD scores were lower in recipients of DCD livers, most probably because a higher proportion of DCD recipients had cancer as their primary disease. DCD livers were more likely to be used as whole rather than partial grafts. Median graft CIT was significantly lower for DCD livers and there were more ethnicity mismatches in this group.

\section{Graft and patient survival}

Graft loss was higher in DCD recipients (figure 1), with a 3-year graft loss (95\% CI) of $27.3 \%$ (21.8 to 33.9) for 
Table 2 Recipient and operative characteristics by donor type

\begin{tabular}{|c|c|c|c|c|}
\hline $\begin{array}{l}\text { Liver donor type } \\
\text { Recipient and operative characteristics }\end{array}$ & $\operatorname{DCD}(n=352)$ & DBD (n=2220) & p Value & Missing (n) \\
\hline Age, years & $53(9)$ & $52(11)$ & 0.02 & 0 \\
\hline Male sex & $247(70)$ & $1436(65)$ & 0.04 & 0 \\
\hline $\mathrm{BMI}, \mathrm{kg} / \mathrm{m}^{2}$ & $27(5)$ & $27(6)$ & 0.94 & 12 \\
\hline Serum sodium, $\mathrm{mmol} / \mathrm{L}$ & $137(134-140)$ & $137(134-140)$ & 0.38 & 7 \\
\hline Serum potassium, $\mathrm{mmol} / \mathrm{L}$ & $4.2(0.5)$ & $4.2(0.5)$ & 0.23 & 52 \\
\hline Serum creatine, $\mu \mathrm{mol} / \mathrm{L}$ & 89 (72-109) & $86(72-104)$ & 0.92 & 4 \\
\hline Serum albumin, g/L & $32(28-37)$ & $32(27-36)$ & 0.40 & 14 \\
\hline Serum bilirubin, $\mathrm{mmol} / \mathrm{L}$ & $41(21-79)$ & $47(24-100)$ & $<0.01$ & 8 \\
\hline INR & $1.4(1.2-1.6)$ & $1.4(1.2-1.6)$ & 0.90 & 54 \\
\hline UKELD score & $54(50-57)$ & $55(51-59)$ & $<0.01$ & 57 \\
\hline MELD score & $15(11-19)$ & $15(12-20)$ & 0.04 & 57 \\
\hline \multicolumn{5}{|l|}{ Primary liver disease } \\
\hline Cancer & $118(33)$ & $461(21)$ & $<0.01$ & 0 \\
\hline $\mathrm{HCV}$ & 47 (13) & $265(12)$ & & \\
\hline PSC & $23(7)$ & $233(10)$ & & \\
\hline $\mathrm{HBV}$ & $6(2)$ & $52(2)$ & & \\
\hline PBC & $34(10)$ & $238(11)$ & & \\
\hline ALD & $71(20)$ & $516(23)$ & & \\
\hline AID & $22(6)$ & $193(9)$ & & \\
\hline Metabolic & $15(4)$ & $86(4)$ & & \\
\hline Other & $16(5)$ & $176(8)$ & & \\
\hline \multicolumn{5}{|l|}{ Previous abdominal surgery } \\
\hline No & $315(90)$ & $1931(87)$ & 0.15 & 10 \\
\hline Yes & $35(10)$ & $281(13)$ & & \\
\hline \multicolumn{5}{|l|}{ Inpatient and ventilatory status } \\
\hline Outpatient & $313(89)$ & $1877(85)$ & 0.10 & 0 \\
\hline Inpatient, not ventilated & $36(10)$ & $322(14)$ & & \\
\hline Ventilated & $3(1)$ & $21(1)$ & & \\
\hline Days in intensive care & $2(1,4)$ & $2(1,4)$ & 0.38 & 15 \\
\hline \multicolumn{5}{|l|}{ Preoperative renal support } \\
\hline No & $333(95)$ & $2116(96)$ & 0.71 & 7 \\
\hline Yes & $18(5)$ & $98(4)$ & & \\
\hline \multicolumn{5}{|l|}{ Organ type } \\
\hline Whole & $343(97)$ & $1956(88)$ & $<0.01$ & 1 \\
\hline Partial & $9(3)$ & $263(12)$ & & \\
\hline Cold ischaemic time, $\mathrm{h}$ & $6.7(5.6-8.0)$ & $9.5(7.8-11.1)$ & $<0.01$ & 93 \\
\hline Anastomosis time, $\min$ & $41(35-50)$ & $42(36-51)$ & 0.42 & 90 \\
\hline \multicolumn{5}{|l|}{ Ethnicity mismatch } \\
\hline No & $272(77)$ & $1868(84)$ & $<0.01$ & 10 \\
\hline Yes & $79(22)$ & $343(15)$ & & \\
\hline
\end{tabular}

DCD recipients and $18.2 \%$ (16.4 to 20.2 ) for DBD recipients with an unadjusted HR of 1.6 (1.2 to 2.0; table 3). Recipient mortality was also increased with DCD livers (figure 1). Three-year mortality was $14.1 \%$ (12.5 to 16.0 ) for DBD recipients and $19.4 \%$ (14.5 to 25.6) for DCD recipients with an unadjusted mortality $\mathrm{HR}$ of 1.4 (1.1 to 2.0) for use of a DCD donor liver.

After adjustment using the multivariable Cox regression model, we found that the risk of graft loss within 3 years of transplantation in recipients of a DCD donor liver was more than twice that of those receiving a DBD liver: adjusted HR 2.3 (1.7 to 3.0). Adjusted 3-year patient mortality was also significantly higher in recipients of livers from DCD donors: adjusted HR 2.0 (1.4 to 2.8; table 3).

After adjustment using the propensity score analysis, use of a liver from a DCD donor was associated with an adjusted HR of 2.3 (1.3 to 4.1) for graft loss. The adjusted HR for recipient mortality was 2.0 (1.0 to 4.2; table 3).

\section{Centre-specific estimates of DCD risk}

Although the interaction between donor type and centre was not statistically significant for either graft loss 
Figure 1 Graft survival after first elective adult liver transplantation using livers from donation after circulatory death (DCD) donors and donation after brain death (DBD) donors.

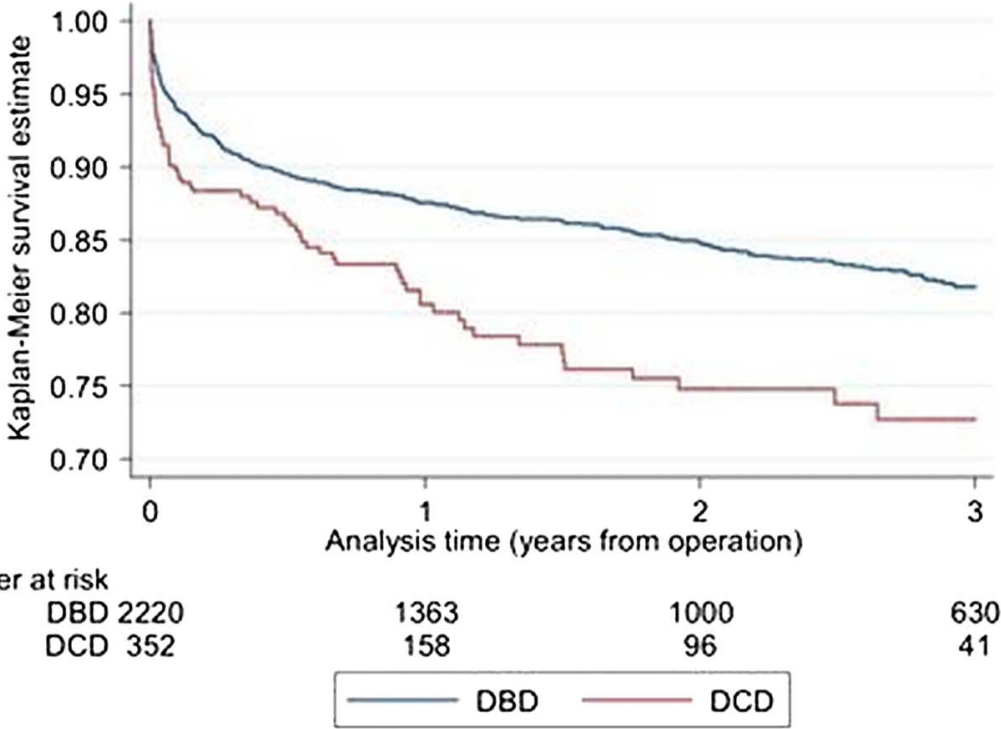

\section{Recipient mortality}

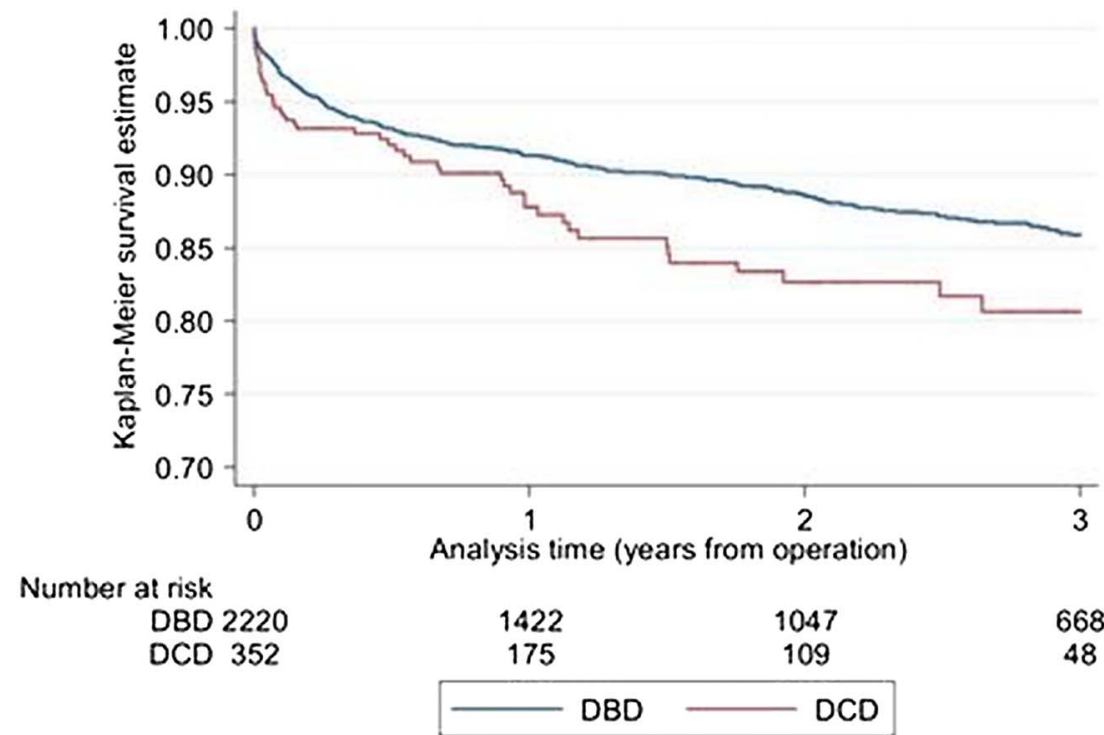

( $p=0.08)$ or recipient mortality $(\mathrm{p}=0.24)$, the relative impact of using DCD livers on graft loss and recipient mortality seemed to vary among the seven transplant centres. Centre-specific adjusted HRs for graft loss and recipient mortality varied from being smaller than 1 to larger than 4 (figure 2).

Table 3 Recipient 3-year graft loss and mortality by donor type

\begin{tabular}{|c|c|c|c|c|}
\hline Liver donor type & & $\begin{array}{l}\text { Unadjusted } \\
\text { HR }(95 \% \mathrm{Cl})\end{array}$ & $\begin{array}{l}\text { Adjusted } \\
\text { HR }(95 \% \mathrm{Cl}) \\
\text { Multivariable model }\end{array}$ & $\begin{array}{l}\text { Adjusted } \\
\text { HR }(95 \% \mathrm{Cl}) \\
\text { Propensity score analysis }\end{array}$ \\
\hline \multicolumn{5}{|c|}{ Three-year graft loss percentage $(95 \% \mathrm{Cl})$} \\
\hline Donation after circulatory death & 27.3 (21.8 to 33.9$)$ & $1.6(1.2$ to 2.0$)$ & $2.3(1.7$ to 3.0$)$ & $2.3(1.3$ to 4.1$)$ \\
\hline Donation after brain death & 18.2 (16.4 to 20.2$)$ & 1 & 1 & 1 \\
\hline \multicolumn{5}{|c|}{ Three-year mortality percentage $(95 \% \mathrm{Cl})$} \\
\hline Donation after circulatory death & 19.4 (14.5 to 25.6$)$ & $1.4(1.1$ to 2.0$)$ & $2.0(1.4$ to 2.8$)$ & 2.0 (1.0 to 4.2$)$ \\
\hline Donation after brain death & 14.1 (12.5.to 16.0$)$ & 1 & 1 & 1 \\
\hline
\end{tabular}

HRs are unadjusted or adjusted based on either a multivariable Cox regression model or propensity score matching. 


\section{Causes of graft loss}

When causes of graft loss were analysed over 3-year posttransplantation, the rates of biliary causes of graft loss were higher in livers from DCD donors $(4 / 72(6 \%))$ than DBD donors $(4 / 330(1 \%$; $=0.04)$. Rates of biliary stricture requiring intervention were very similar between the two groups (DCD donors 13/347 (4\%) vs DBD donors $81 / 2193$ (4\%; $=0.96)$ ).

\section{DISCUSSION}

Recipients of DCD livers, after risk adjustment, have approximately twice the risk of graft loss and death within 3 years of transplantation than recipients of livers from DBD donors. This is the first study that has analysed risk-adjusted outcomes in recipients of livers from DCD donors outside of the USA. Although US-based studies have reported on larger numbers of DCD liver transplant recipients, ${ }^{6} 7913$ rates of DCD liver usage in the UK are more than double that of the USA. ${ }^{3} 14$

Our results are in contrast with single-centre reports that demonstrate good short-term results with liver transplantation from DCD donors, ${ }^{12}{ }^{26}$ with graft loss and patient mortality similar to those from DBD donors. ${ }^{27-29}$ However, it is important to note that we found that the impact of using DCD livers on graft loss and recipient mortality seemed to differ among the seven UK transplant centres, although these differences did not reach statistical significance. This finding indicates that it is important to investigate centre-specific practices that may impact on the outcomes of transplantation of DCD livers, including the selection of DCD grafts, definition of warm ischaemic limits and procurement and implantation techniques.

Risk factors for graft loss and patient mortality are unevenly distributed between DBD and DCD donors and recipients. For example, partial organs were more often used for DBD recipients than for DCD recipients. However, risk adjustment or matching techniques ${ }^{30}$ are therefore crucial for a valid comparison of outcomes. Because estimates from multivariable models can be less robust when many factors are included, we also used propensity score matching. Reassuringly, both risk-adjustment techniques gave similar HRs for graft loss and recipient death.

In the UK, DCD liver donors are marginally older and have longer times from withdrawal of life-sustaining treatment to cold perfusion than in the USA. ${ }^{6} 7131431$ These differences are likely to reflect a wider acceptance of transplantation of DCD livers in the UK than in the USA and that treatment withdrawal in the UK takes place in the intensive care unit or the anaesthetic room but not in theatre itself. However, CITs are shorter for DCD livers in the UK, even taking into account differences in definitions between the two countries. ${ }^{6} 71332$ This may be due to geographical differences between the two countries (ie, longer distances between procuring and implanting centres) or an increased willingness on the part of UK surgeons to begin the recipient operation before the organ arrives at the implanting centre.

Transplanted livers from DCD donors appear particularly susceptible to biliary complications, most commonly ischaemic cholangiopathy, which is thought to occur as a result of warm ischaemic damage to the biliary epithelium sustained during the procurement process. ${ }^{10} 33-36$ We examined rates of graft loss from biliary causes and found that this was a relatively rare cause of graft loss in DCD as well as in DBD recipients. In addition, there was no difference in the proportion of DCD and DBD recipients who required an intervention for biliary strictures. Although these findings concur with previous reports suggesting that ischaemic cholangiopathy is not a major problem in UK recipients of livers from DCD donors, ${ }^{26}{ }^{27}$ it should be recognised that analyses of national registry data are prone to under-reporting of postoperative complications.

Unfortunately, data on time from withdrawal of lifesustaining treatment to cardiac arrest were missing in more than $50 \%$ of DCD donors and therefore the impact of this variable on outcome was not assessed. Prolonged time from cardiac arrest to cold perfusion has been shown to be a risk factor for the development of ischaemic cholangiopathy ${ }^{35}$ and would therefore be expected to lead to decreased graft survival. We found no significant association (data not shown). This is again likely to be due to lack of power or to most DCD donors having similar times, with an IQR of just $5 \mathrm{~h}$.

Defining acceptable warm ischaemic limits for livers from DCD donors is hampered by the lack of data on donor cardiorespiratory parameters after treatment withdrawal. Some controlled DCD donors have prolonged periods of cardiorespiratory stability before dying rapidly. It is, therefore, possible that the duration of hypotension or hypoxia has a greater impact on subsequent graft viability than the duration from treatment withdrawal to cardiac arrest or cold perfusion. ${ }^{87}$ National prospective data collection of postwithdrawal cardiorespiratory parameters in Maastricht III DCD donors has therefore been initiated in both the UK and the USA. ${ }^{8}$ Further research is also required into the impact of procurement techniques and preservation fluids on graft function, ${ }^{38}$ and the emerging role of machine perfusion. ${ }^{29}$

The allocation of deceased donor livers in the UK is currently on a local basis, with national organ sharing only for those patients with acute liver failure reaching specific criteria. ${ }^{39}$ Although local allocation reduces CIT, which is an important risk factor for graft survival, the current system raises issues of equity of access to a national resource. The ultimate aim of our analyses of national data is to inform discussions on how best to utilise this resource. ${ }^{40}$ For example, one could use our results as further support for not using livers from DCD donors for patients with a low risk of death on the waiting list as these recipients are able to wait for a graft that is more likely to have a favourable long-term outcome. An exception could be made for patients with 
Figure 2 Centre-specific HR and $95 \% \mathrm{Cl}$ comparing 3-year graft loss (top figure) and recipient mortality (bottom figure). HRs greater than 1 indicate that risks of loss or mortality are greater with donation after circulatory death than with donation after brain death livers.

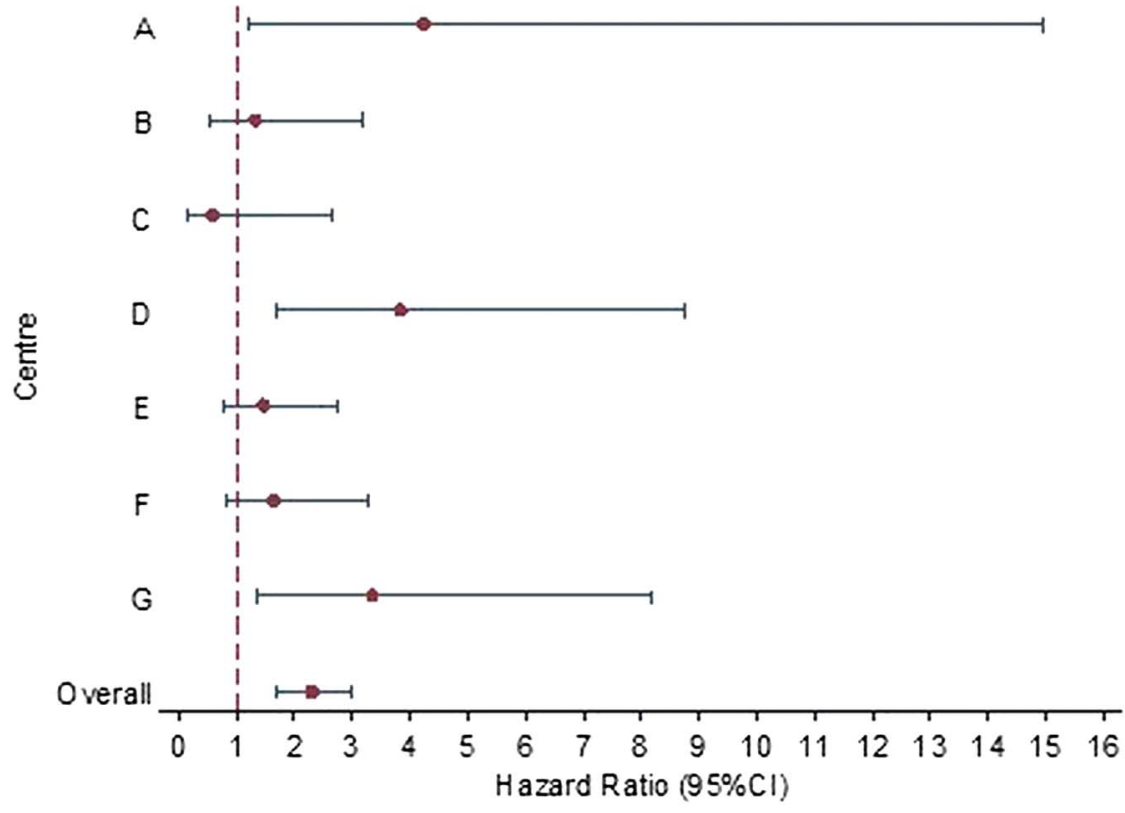

Recipient mortality

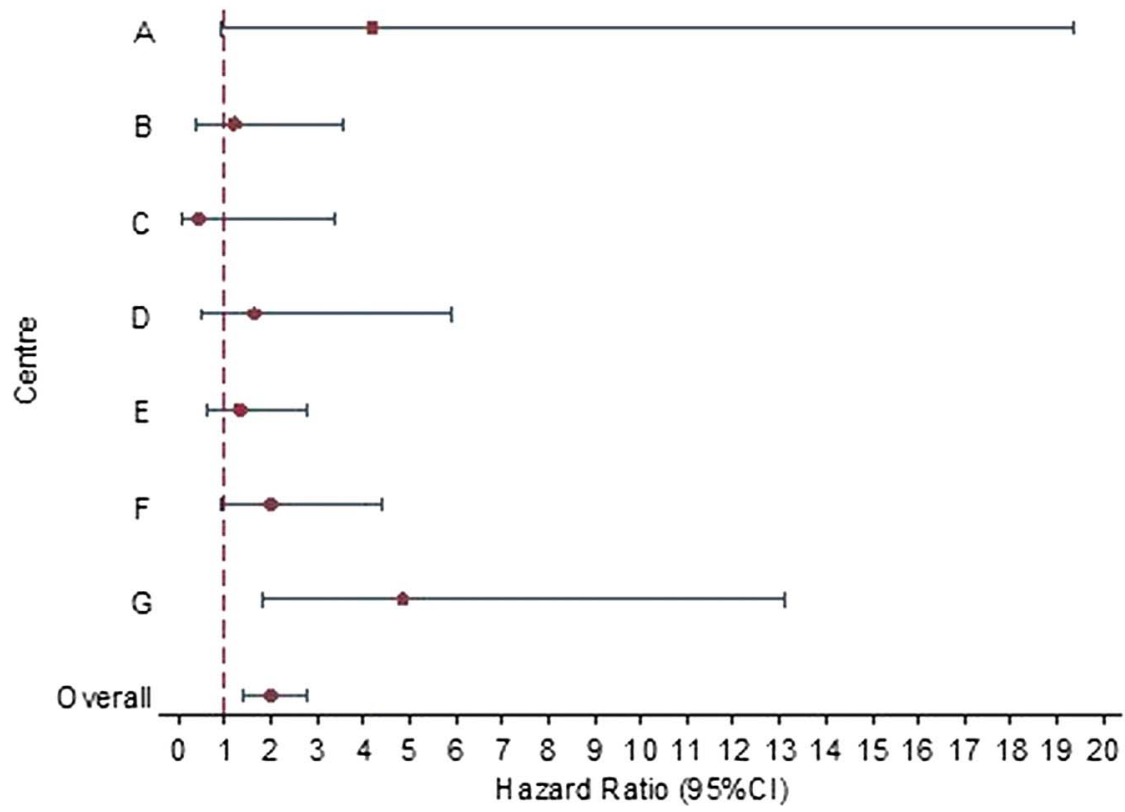

hepatocellular carcinoma. Although, these patients generally have low UKELD scores-indicating a low risk of mortality on the waiting list - they have a high risk of disease progression, which is an additional argument to use livers from DCD donors for this group.

The relative benefit associated with transplantation of a DCD versus a DBD donor liver is expected to be dependent not only on donor and recipient factors, but also on the overall availability of donor livers within each region or country, the rate of deaths on the waiting list and the impact of DCD transplantation on the subsequent need for retransplantation. ${ }^{41}$ Allocation policies also need to determine whether DCD organs are to be distributed on the basis of utility, urgency or overall survival benefit. ${ }^{42}$ Although livers transplanted from DCD donors have inferior outcomes to those from DBD donors, they remain a valuable additional source of grafts, especially in countries with relatively low rates of DBD organ donation.

Acknowledgements The authors would like to thank all the seven UK liver transplant centres for providing data to the UK Liver Transplant Audit and all those involved in collecting and handling liver transplant data at the National Health Service (NHS) Blood and Transplant authority, and Kerri Barber, lead liver transplant statistician at the authority.

Contributors CJC, AEG, SCC and JHPVDM designed the study. SCC analysed the data. All authors contributed to the interpretation of the results. CJC wrote the first draft of the manuscript supported by SCC and JHPVDM. All authors commented on later drafts of the manuscript. JHPVDM is the guarantor.

Funding NHS National Specialised Commissioning Group.

Competing interests None. 
Provenance and peer review Not commissioned; externally peer reviewed.

Data sharing statement No additional data are available.

Open Access This is an Open Access article distributed in accordance with the Creative Commons Attribution Non Commercial (CC BY-NC 3.0) license, which permits others to distribute, remix, adapt, build upon this work noncommercially, and license their derivative works on different terms, provided the original work is properly cited and the use is non-commercial. See: http:// creativecommons.org/licenses/by-nc/3.0/

\section{REFERENCES}

1. Kootstra G, Daemen JH, Oomen AP. Categories of non-heart-beating donors. Transplant Proc 1995;27:2893-4.

2. Jimenez-Galanes S, Meneu-Diaz MJ, Elola-Olaso AM, et al. Liver transplantation using uncontrolled non-heart-beating donors under normothermic extracorporeal membrane oxygenation. Liver Transpl 2009;15:1110-18

3. Thuluvath PJ, Guidinger MK, Fung JJ, et al. Liver transplantation in the United States, 1999-2008. Am J Transplant 2010;10 (4 Pt 2):1003-19.

4. Dominguez-Gil $\mathrm{B}$, Haase-Kromwijk $\mathrm{B}$, Van Leiden $\mathrm{H}$, et al. Current situation of donation after circulatory death in European countries. Transpl Int 2011;24:676-86.

5. Abt PL, Desai NM, Crawford MD, et al. Survival following liver transplantation from non-heart-beating donors. Ann Surg 2004;239:87-92.

6. Mateo R, Cho $\mathrm{Y}$, Singh $\mathrm{G}$, et al. Risk factors for graft survival after liver transplantation from donation after cardiac death donors: an analysis of OPTN/UNOS data. Am J Transplant 2006;6:791-6.

7. Lee KW, Simpkins CE, Montgomery RA, et al. Factors affecting graft survival after liver transplantation from donation after cardiac death donors. Transplantation 2006;82:1683-8.

8. Mathur AK, Heimbach J, Steffick DE, et al. Donation after cardiac death liver transplantation: predictors of outcome. Am J Transplant 2010;10:2512-19.

9. Jay C, Skaro A, Ladner D, et al. A comprehensive risk assessment of mortality following donation after cardiac death liver transplantan analysis of the national registry. J Hepatol 2011;44:808-13.

10. Jay CL, Lyuksemburg V, Ladner DP, et al. Ischemic cholangiopathy after controlled donation after cardiac death liver transplantation: a meta-analysis. Ann Surg 2011;253:259-64.

11. Renz JF. Is DCD for liver transplantation DNR? Am J Transplant 2008;8:485-8.

12. Muiesan P, Girlanda R, Jassem W, et al. Single-center experience with liver transplantation from controlled non-heartbeating donors: a viable source of grafts. Ann Surg 2005;242:732-8.

13. Merion RM, Pelletier SJ, Goodrich N, et al. Donation after cardiac death as a strategy to increase deceased donor liver availability. Ann Surg 2006;244:555-62.

14. NHS Blood and Transplant. Transplant activity in the UK. 2008.

15. http://www.rcseng.ac.uk/surgeons/research/surgical-research/docs/ uk-liver-transplant-audit-report-2011 (accessed 14 Aug 2012).

16. Hartley P, Petruckevitch A, Reeves B, et al.; On behalf of the Steering Group of the UK Liver Transplantation Audit. The National Liver Transplantation audit: an overview of patients presenting for liver transplantation from 1994 to 1998. Br J Surg 2001;88:52-8.

17. Jacob M, Copley LP, Lewsey JD, et al. Pretransplant MELD score and post liver transplantation survival in the UK and Ireland. Liver Transpl 2004;10:903-7.

18. van der Meulen JH, Jacob M, Copley L. Assessing the quality of the data in a transplant registry: the European Liver Transplant Registry. Transplantation 2003;75:2164-7.

19. Reich DJ, Mulligan DC, Abt PL, et al. ASTS recommended practice guidelines for controlled donation after cardiac death organ procurement and transplantation. Am J Transplant 2009;9:2004-11.

20. Neuberger J, Gimson A, Davies M, et al. Selection of patients for liver transplantation and allocation of donated livers in the UK. Gut 2008;57:252-7
21. Barber K, Madden S, Allen J, et al. Elective liver transplant list mortality: development of a United Kingdom End-Stage Liver Disease score. Transplantation 2011;92:469-76.

22. Kamath $\mathrm{PS}$, Wiesner $\mathrm{RH}$, Malinchoc $\mathrm{M}$, et al. A model to predict survival in patients with end-stage liver disease. Hepatology 2001;33:464-70.

23. Rosenbaum PR, Rubin DB. Reducing bias in observational studies using subclassification on the propensity score. J Am Stat Assoc 1984;79:516-24.

24. Austin PC, Mamdani MM. A comparison of propensity score methods: a case-study estimating the effectiveness of post-AMI statin use. Stat Med 2006;25:2084-106.

25. White IR, Royston P, Wood AM. Multiple imputation using chained equations: issues and guidance for practice. Stat Med 2011;30:377-99.

26. Tariciotti L, Rocha C, Perera MT, et al. Is it time to extend liver acceptance criteria for controlled donors after cardiac death? Transplantation 2011;92:1140-6.

27. Deoliveira ML, Jassem W, Valente $\mathrm{R}$, et al. Biliary complications after liver transplantation using grafts from donors after cardiac death: results from a matched control study in a single large volume center. Ann Surg 2011;254:716-23.

28. Mallik M, Callaghan CJ, Hope M, et al. Comparison of liver transplantation outcomes from adult split liver and circulatory death donors. Br J Surg 2012;99:839-47.

29. Grewal HP, Willingham DL, Nguyen J, et al. Liver transplantation using controlled donation after cardiac death donors: an analysis of a large single-center experience. Liver Transp/ 2009;15:1028-35.

30. Pine JK, Aldouri A, Young AL, et al. Liver transplantation following donation after cardiac death: an analysis using matched pairs. Liver Transpl 2009;15:1072-82.

31. Feng S, Goodrich NP, Bragg-Gresham JL, et al. Characteristics associated with liver graft failure: the concept of a donor risk index. Am J Transplant 2006;6:783-90.

32. Berg CL, Steffick DE, Edwards EB, et al. Liver and intestine transplantation in the United States 1998-2007. Am J Transplant 2009;9:907-31.

33. Abt $\mathrm{P}$, Crawford $\mathrm{M}$, Desai $\mathrm{N}$, et al. Liver transplantation from controlled non-heart-beating donors: an increased incidence of biliary complications. Transplantation 2003;75:1659-63.

34. Foley DP, Fernandez LA, Leverson G, et al. Biliary complications after liver transplantation from donation after cardiac death donors: an analysis of risk factors and long-term outcomes from a single center. Ann Surg 2011:253:817-25.

35. Taner CB, Bulatao IG, Willingham DL, et al. Events in procurement as risk factors for ischemic cholangiopathy in liver transplantation using donation after cardiac death donors. Liver Transpl 2012;18:100-11.

36. Chan EY, Olson LC, Kisthard JA, et al. Ischemic cholangiopathy following liver transplantation from donation after cardiac death donors. Liver Transpl 2008;14:604-10.

37. Ho KJ, Owens CD, Johnson SR, et al. Donor postextubation hypotension and age correlate with outcome after donation after cardiac death transplantation. Transplantation 2008;85:1588-94.

38. Brockmann JG, Vaidya A, Reddy S, et al. Retrieval of abdominal organs for transplantation. Br J Surg 2006;93:133-46.

39. de Rougemont O, Breitenstein S, Leskosek B, et al. One hour hypothermic oxygenated perfusion (HOPE) protects nonviable liver allografts donated after cardiac death. Ann Surg 2009;250:674-83.

40. Morris PJ, Johnson RJ, Fuggle SV, et al.; HLA Task Force of the Kidney Advisory Group of the United Kingdom Transplant Support Service Authority (UKTSSA). Analysis of factors that affect outcome of primary cadaveric renal transplantation in the UK. Lancet 1999;354:1147-52.

41. Selck FW, Grossman EB, Ratner LE, et al. Utilization, outcomes, and retransplantation of liver allografts from donation after cardiac death: implications for further expansion of the deceased-donor pool. Ann Surg 2008;248:599-607.

42. Merion RM, Sharma P, Mathur AK, et al. Evidence-based development of liver allocation: a review. Transpl Int 2011;24:965-72. 